Elsevier required licence: (C) <2019>. This manuscript version is made available under the CC-BY-NCND 4.0 license http://creativecommons.org/licenses/by-nc-nd/4.0/

The definitive publisher version is available online at

[https://www.sciencedirect.com/science/article/pii/S2214714419306737?via\%3Dihub] 


\title{
Optimization of module Pressure Retarded Osmosis membrane for Maximum Energy Extraction
}

\author{
Yingxue Chen ${ }^{1}$, Adnan Alhathal Alanezi ${ }^{3}$, John Zhou $^{2}$, Ali Altaee ${ }^{2}$, M Hasan \\ Shaheed ${ }^{1 *}$ \\ ${ }^{1}$ School of Engineering and Materials Science, Queen Mary University of London, London, E1 4NS, UK. \\ ${ }^{2}$ University of Technology Sydney, School of Civil and Environmental Engineering, Ultimo, NSW 2007, \\ Australia. \\ ${ }^{3}$ Department of Chemical Engineering Technology, College of Technological Studies, The Public Authority \\ for Applied Education and Training (PAAET), P.O. Box 117, Sabah AlSalem 44010, Kuwait
}

\begin{abstract}
A full-scale Pressure Retarded Osmosis process (PRO) is optimized in non-ideal operating conditions using Grey Wolf Optimization (GWO) algorithms. Optimization process included the classical parameters that previous studies recommended such as operating pressure, and feed and draw fractions in the mixture solution. The study has revealed that the recommended operating pressure $\Delta P=\Delta \pi / 2$ and the ratio of feed or draw solution to the total mixture solution, $\sim 0.5$, in a laboratory scale unit or in an ideal PRO process are not valid in a non-ideal full-scale PRO module. The optimization suggested that the optimum operating pressure is less than the previously recommended value of $\Delta P=\Delta \pi / 2$. The optimization of hydraulic pressure resulted in $4.4 \%$ increase of the energy output in the PRO process. Conversely, optimization of feed fraction in the mixture has resulted in $28 \%$ to $70 \%$ higher energy yield in a single-module PRO process and $9 \%$ to $54 \%$ higher energy yield in a four-modules PRO process. The net energy generated in the optimized PRO process is higher than that in the unoptimized (normal) PRO process. The findings of this study reveal the significance of incorporating machine-learning algorithms in the optimization of PRO process and identifying the preferable operating conditions.
\end{abstract}

Keywords: Pressure Retarded Osmosis, renewable Energy, Grey Wolf Optimization, Salinity Gradients, Osmosis Power Plant

\section{Introduction}

Pressure retarded osmosis (PRO) has been broadly investigated for power generation from a salinity gradient resource [1-5]. The technology has been demonstrated in pilot and laboratory scales with the potential of being commercialized as a source of renewable energy [6-7]. The PRO process converts chemical potential across a semipermeable membrane into a hydraulic energy using concentrated draw solution and diluted feed solution salinity gradient. Feed and draw solutions have a significant impact on the energy output of the PRO process that can be increased by optimizing the applied hydraulic pressure on the draw solution side [8]. Furthermore, energy output in the PRO process is sensitive to the volume of the feed or draw solution in the total mixture [1,9]. Optimization of the PRO process is a critical process to maximize the energy output from a salinity gradient resource although former studies focused mostly on the optimization and performance of a laboratory-scale PRO or assuming an ideal system, ignoring the effects of concentration polarization (CP) effects $[8,10]$. This resulted in a misunderstanding of the capability of the PRO process and widened the discrepancies between laboratory and field results. To date, studies carried out on the performance and optimization of a full-scale PRO module are, unfortunately, scarce and hence new studies about

\footnotetext{
* Corresponding author.

E-mail address: Ali.Altaee@uts.edu.au (A. Altaee).
} 
the performance of full scale PRO module are required for improving the potential of real-time process implementation and applications.

Performance of the PRO process in a full-scale module is different to that in a flat-sheet laboratory scale unit. Based on the laboratory size experiments, most studies have used equal feed and draw solutions flow rates, which ignored the effect of dilution and concentrations along the PRO module [3, 8]. Masaru and Masayuki [6] performed a pilot plant test for power generation using eight 10-in, hollow fiber membrane modules. The PRO achieved a power density equal to $4.4 \mathrm{~W} / \mathrm{m}^{2}$, which is closer to the minimum theoretical threshold value for an economic PRO process [7]. The study did not perform an optimization process to enhance the energy output in the PRO process. Achilli et al, [10] conducted a laboratory test on a flat sheet PRO unit and concluded that maximum power density occurs at a hydraulic pressure equal to $\Delta \pi / 2$. The study, however, did not investigate the effect of varying the feed or draw solution flow rate on the power generation in the PRO process. Elimelch et al, [8] investigated energy yield from various salinity gradient resources in a PRO module, suggesting that the maximum specific energy was achieved at hydraulic pressure and feed or draw fraction in the mixture equal to $\Delta P=\Delta \pi / 2$ and 0.5 respectively. The study assumed an ideal system and ignored the effects of $\mathrm{CP}$ in the $\mathrm{PRO}$ process. Altaee et al, [3] performed a thermodynamic analysis study on a full scale PRO module and found that increasing the number of modules in the pressure vessel maximized the energy yield of the PRO system. The study was performed at hydraulic pressure and feed or draw fraction in the mixture equal to $\Delta P=\Delta \pi / 2$ and 0.5 respectively. In a different study, Altaee et al, performed PRO performance analysis study considering the impact of feed and draw flow rates, hydraulic pressure, and membrane area on the energy output in the PRO process [22]. The study showed that increasing the flow rate of feed and draw solution reduced the effects of $\mathrm{CP}$ and improved the performance of PRO process. The study, however, considered neither the impact of CP nor the impact of module length of the process performance. Yang and co-workers developed a numerical simulation procedure for a counter-current flow PRO process [11]. The numerical model predicted the flow rates and salt concentrations along the membrane channels for any feed fractions. However, the modelling results are only valid for an ideal PRO process and ignored the effects of CP along the PRO module.

Salinity gradient processes experiences dynamic changes in the full-scale PRO element due to the continuous dilution and concentration of the draw and feed solutions, respectively $[3,9$, $23]$. M. Li $[12,13]$ provided a dimensionless design model to evaluate the impact of operating parameters on the performance of the PRO process. The study concluded that the concentration and dilution of feed and draw solutions, respectively, reduces the power density and the optimal $\Delta P$ shifts away from $\Delta \pi / 2$ value. In practice, the pressure vessel may contain several PRO elements packed in a series and operates under a constant hydraulic pressure while the concentrations of the feed and the draw solution undergo continuous changing along the PRO module and in each module in the pressure vessel. As such, the optimum value of hydraulic pressure for a laboratory scale PRO unit and equal to $\Delta P=\Delta \pi / 2$ would not be valid for a fullscale PRO element or a pressure vessel of multi PRO elements. Although the optimum value of hydraulic pressure $\Delta P=\Delta \pi / 2$ has been validated on a laboratory scale unit, but it is still used in pilot plant tests. Module optimization requires large system setup and testing, which is time and labour intensive. Several studies used metaheuristic based machine learning algorithms methods in the optimization of engineering and renewable energy processes and demonstrated good results [4, 13-19]. Machine-learning based optimisation methods offer unique merits that include i) these algorithms result in simple concepts which can be employed easily; ii) they offer derivative-free optimization method suitable to be used in a wide range of applications; iii) the population-based strategy of these algorithms results in the local optimal stagnation avoidance; iv) they are well suited to be implemented in multi-objective problems 
[13-16]. The Grey Wolf Optimization (GWO) method used in this study is a machine learning optimization method widely known for its efficiency and ease of implementation.

In the current study, we performed optimization on a full-scale PRO membrane considering a none-ideal system to accounts for the impact of CP. Optimization of PRO module consists of one to four modules was performed and energy yield in the PRO process were compared since data on multi-module PRO system are scarce in literature. The optimum hydraulic pressure and feed and draw fractions in the mixture was obtained for a number of salinity gradient resources of different feed and draw solution concentrations. We applied a machine learning algorithms software in the optimization of the PRO process. The software was applied not only to identify the optimum hydraulic pressure but also to find the optimum feed and draw solution fractions in the mixture for a number of salinity gradient resources. The approach has resulted in a staggering improvement in the energy extraction from the scaled-up PRO process.

\section{Methods and Modelling}

Four types of salinity gradient resources; these are Dead Sea-seawater (5M-0.6M NaCl), Dead Sea-Reverse Osmosis brine $(5 \mathrm{M}-1.2 \mathrm{M} \mathrm{NaCl})$, seawater-wastewater effluent $(0.6 \mathrm{M}$ $0.02 \mathrm{M} \mathrm{NaCl})$, and $\mathrm{ROb}$-wastewater effluent $(1.2 \mathrm{M}-0.02 \mathrm{M} \mathrm{NaCl})$, were evaluated for power generation in the PRO process. These salinity gradients were abundant in the environment and commonly investigated in literature $[1,20]$. A computer model was applied to calculate the efficiency of the PRO and the system optimization was performed using GWO algorithms.

\subsection{PRO model}

A pre-developed computer model was applied to estimate water flux in the PRO module [1, $9,21]$. The computer model was validated using experimental data from a pilot plant study [Appendix A.1]. Water flux in the PRO membrane was calculated using Equation $1[1,24]$ :

$$
J_{w, n x}=A_{w}\left(\frac{\left(\phi R T C_{D i, n x}\left(1+\frac{Q_{D i, n x}}{Q_{D o, n x}}\right) / 2\right) \exp \left(\frac{-J_{w}}{k_{d}}\right)-\left(\phi R T C_{F i, n x}\left(1-\frac{Q_{F i, n x}}{Q_{F o, n x}}\right) / 2\right) \exp \left(J_{w} K+\frac{J_{w}}{k_{f}}\right)}{1+\frac{B}{J_{w-x}}\left(\exp \left(J_{w} K+\frac{J_{w}}{k_{f}}\right)-\exp \left(\frac{-J_{w}}{k_{d}}\right)\right)}-\Delta P\right)
$$

where, $\varnothing$ is number of ions in the solution, $R$ is the gas constant, and $T$ is the temperature in Kelvin, $C_{D i, n x}$ and $C_{F i, n x}$ are the bulk concentrations of the draw and feed solutions at distance $x$, respectively; $n$ is the number of PRO module in the pressure vessel, $k_{d}$ and $k_{f}$ are the mass-transfer coefficients of the draw and feed solutions, respectively $(\mathrm{m} / \mathrm{h}) ; K$ is the solute resistivity in the case where the feed is facing the feed solution; $A_{w}$ is the membrane permeability coefficient, and $B$ is the salt permeability coefficient. $A_{w}$ and $B$ were assumed to be $1.23 \mathrm{~L} / \mathrm{hm}^{2} \cdot$ bar and $2.6 \mathrm{~kg} / \mathrm{hm}^{2}$ respectively, $k_{d}=k_{f}=0.18 \mathrm{~m} / \mathrm{h}$, and $K=31 \mathrm{~h} / \mathrm{m} \mathrm{[4]}$. The study assumes using a spiral wound PRO module and pressure drop in the module is insignificant. Equation 1 accounts for CP and external resistance in the PRO membrane [9, 21]. It calculates the water flux in a PRO membrane operating in the PRO mode (draw solution faces the membrane active layer; DS-AL). Detailed information about the derivation of Equation 1 is found in literature [3]. The fractions of draw and feed volumes, $\theta_{D}$ and $\theta_{F}$ respectively, in the mixture solution were calculated from the following equations: 


$$
\begin{aligned}
& \theta_{D}=\frac{v_{D}}{v_{D}+v_{F}} \\
& \theta_{F}=\frac{v_{F}}{v_{D}+v_{F}}
\end{aligned}
$$

where, $V_{D}$ and $V_{F}$ are the volumetric flow rate of draw and feed solutions. Different $\theta_{D}$ and $\theta_{F}$ ratios were tested and their effects on the PRO performance were investigated. Furthermore, the specific energy output in the PRO process, $E_{S}$, was calculated at different operating conditions using the following expression:

$$
E s=\frac{\Delta P^{*} Q_{p}}{Q_{D}+Q_{F}}
$$

where, $\Delta P$ is the hydraulic pressure of the draw solution entering the hydroturbine (bar) and $Q_{p}, Q_{D}, Q_{F}$ are the permeate, draw solution and feed solution flow rates, respectively. Specific energy output from the optimized PRO system was compared with that from the unoptimized PRO process. In practice, internal and external CP, ICP and ECP respectively, can be mitigated by varying the feed and flow rates in the PRO module but that would compromise the specific energy output in the PRO process unless the flow rates are carefully optimized [21, 22].

\subsection{Optimization of PRO using GWO}

In order to extract the maximum energy from a PRO process, several operating variables need to be optimized. These include hydraulic pressure as well as the flow rates of draw and feed solutions. As reported in the literature [4], PRO process on the basis of only hydraulic pressure was optimized in the form of maximum power point tracking (MPPT) using P\&O and IMR methods. However, these conventional methods are limited with low convergence and less computation rate, resulting in a low energy efficiency. Moreover, key input parameters of these methods require careful adjustments with respect to the nature of a problem and its operating scenario. In addition, conventional MPPT methods are not suitable for a full-scale PRO process [25].

Considering the limitations of conventional optimization algorithms as mentioned above, a swarm intelligence-based approach is utilized in this research as an optimal tool for a full-scale PRO process. The main advantages of metaheuristic methods are that they are derivation-free and are therefore able to deal with problem with less computational cost, they have the ability to provide global solutions and are facilitated with higher search ability. As a typical swarm intelligence algorithm, GWO has attracted significant attention from the scientific community to design efficient control and optimization techniques in engineering applications. It is a relatively new member of the metaheuristic algorithms family, proposed by Mirjalili and Lewis [14] inspired by the leadership pyramid mechanism grey wolves. In addition to the common merits of evolutionary techniques, GWO has its unique impassive characteristics. It can be utilized in more complex cases with reduced searching parameters, free initialized derivation parameters and large solution space, resulting in its flexibility and stability in handling multiobjective and large-scale problem. The applications of GWO is therefore utilized in many fields including control system, energy system, optimization system, etc by researchers in a short period of time. Sultana et. al. [15] used a GWO algorithm for the optimization of system components in power plants. Later, a GWO algorithm was applied for a multi-objective problem in the electric power systems by Aziziyahed et. al. [16]. Researchers [17, 18] proposed a GWO combined with Maximum Power Point Tracking (MPPT) algorithms for PV system. 
The advantage of GWO in terms of convergence and tracking efficiency for optimal energy extraction from PV systems is illustrated in Table I. Rao and Kumar [26] and Kumar et al. [27] have investigated the ability of GWO and other methods such as PSO to extract maximum energy from a PV system. Both PSO and GWO demonstrated high efficiency in optimization the performance of PV systems. Rao and Kumar [26] analysed and compared GWO and other conventional methods using simulation, while Kumar et al. [27] validated the prior performance of GWO by utilizing the methods in hardware. In both studies, GWO is proven to have the ability to achieve a higher energy efficiency.

TABLE I

COMPARISON OF OPTIMIZATION TECHNIQUES IN LITERATURE

\begin{tabular}{rcccccc}
\hline \multirow{2}{*}{ Method } & \multicolumn{3}{c}{ Convergence (W) } & \multicolumn{2}{c}{ Tracking efficiency (\%) } \\
\cline { 2 - 7 } PSO [26] & Pattern-1 & Pattern-2 & Pattern-4 & Pattern-1 & Pattern-2 & Pattern-4 \\
\hline GWO [26] & 319.2 & 329.5 & 251.5 & 99.75 & 99.84 & 99.88 \\
& 319.4 & 329.6 & 251.6 & 99.81 & 99.87 & 99.92 \\
\hline PSO [27] & Pattern-4 & Pattern-5 & Pattern-6 & Pattern-4 & Pattern-5 & Pattern-6 \\
\hline GWO [27] & 522.93 & 353.425 & 437.97 & 99.99 & 99.97 & 99.97 \\
\hline
\end{tabular}

Pattern 1 to 3 are three 2S2P PV configurations under different shading pattern [26].

Pattern 4 to 6 are different PV curve configurations in shading [27]. Pattern-4 and Pattern-5: 4S; Pattern-6: 2S2P.

However, GWO-based optimization in the form of MPPT for a PRO system has not yet been reported in the literature to utilize the unique merits of this optimization mechanism in extracting the maximum power from a full-scale PRO process. Thus, in this work, GWO is utilized to yield the optimal energy from a full scale PRO system.

\section{Optimization of the full-scale PRO module}

GWO was applied for the optimization of the PRO process and identifying the optimum operation conditions. For a given salinity gradient resource, hydraulic pressure and flow rates are the most critical operating parameters that affect the energy output of the process. These parameters were considered in the optimization of the PRO process.

\subsection{Optimization of Hydraulic Pressure}

As reported in the literatures, the hydraulic pressure is the most critical operating parameter that controls the efficiency of the PRO process $[8,22]$. Most studies agreed that the maximum power generation in the PRO process occurs at $\Delta P=\Delta \pi / 2[8,10]$. However, this conclusion was based on a laboratory scale PRO unit or an ideal PRO system (ignoring the effects of CP) $[8,10]$. We performed GWO optimization to identify the optimum operating pressure for a PRO system comprising multi-modules packed in a pressure vessel and results were compared with a conventional PRO system. The assumptions made here are i) PRO module length is 1 metre and ii) 1 to 4 modules are packed in the pressure vessel [3]. Previous studies [3] revealed that $4 \mathrm{FO}$ modules would results in a maximum power density for a number of salinity gradient 
resources. Energy output in the PRO system consisting of 1 to 4 PRO module was calculated at $Q_{F}=Q_{D}$ and $\Delta P=\Delta \pi / 2$ and compared with that of the optimized PRO system at $Q_{F}=Q_{D}$ and optimal $\Delta \mathrm{P}$. GWO results show 1 to $4.5 \%$ increase in the specific energy output was achieved by adjusting the hydraulic pressure (Figure 1). Most interestingly, maximum specific energy output occurred at a hydraulic pressure less than $\Delta \pi / 2$ and that was for all salinity gradients (Figure 1A). It is also observed that the maximum specific energy increased by increasing number of the PRO modules (Figure 1B). Adding extra PRO modules improves the process of chemical potential conversion into a hydraulic energy and hence maximized the amount of energy yield from the salinity gradient resource. In general, the maximum specific power generation was $0.657 \mathrm{kWh} / \mathrm{m}^{3}$ in the PRO process with $5 \mathrm{M}-0.6 \mathrm{M}$ salinity gradient resource followed by $5 \mathrm{M}-1.2 \mathrm{M}, 1.2 \mathrm{M}-0.02 \mathrm{M}$, and $0.6 \mathrm{M}-0.02 \mathrm{M}$ salinity gradient, respectively [Figure 1C].

Figure 1A shows that the optimum hydraulic pressure was 12 bar for $0.6 \mathrm{M}-0.02 \mathrm{M}$ salinity gradient and the number of PRO modules in the pressure vessel did not significantly affect it. For the rest salinity gradients, the optimum hydraulic pressure decreased with the increase of PRO modules in the pressure vessel. In a four-modules system, 5M-0.6M salinity gradient showed the largest difference in the hydraulic pressure between the optimized and unoptimized PRO process followed by $2 \mathrm{M}-0.02 \mathrm{M}, 5 \mathrm{M}-1.2 \mathrm{M}$ and $0.6 \mathrm{M}-0.02 \mathrm{M}$ salinity gradients, respectively. For 5M-0.6M salinity gradient, the optimum hydraulic pressure in a PRO system consisting of four modules packed in series was 87 bar and the maximum specific energy output was $0.99 \mathrm{kWh} / \mathrm{m}^{3}$. The corresponding hydraulic pressure and maximum specific energy output in the normal PRO process (without optimization) were 106 bar and $0.94 \mathrm{kWh} / \mathrm{m}^{3}$ respectively. For 4 elements PRO system, the optimized hydraulic pressure is $87,80,23$, and 12 bar for $5 \mathrm{M}$ $0.6 \mathrm{M}, 5 \mathrm{M}-1.2 \mathrm{M}, 1.2 \mathrm{M}-0.02 \mathrm{M}$, and $0.6 \mathrm{M}-0.02 \mathrm{M}$ salinity gradient, respectively. The optimization of the PRO process resulted in a slight improvement in the energy output $(\sim 4.5 \%)$ but there was also a tangible drop in the optimum operating pressure. In practice, this suggests that optimized PRO system require lower pressure and pumping energy than a normal system for operation. Furthermore, characteristics of the membrane, such as mechanical strength, are different in the optimized and unoptimized PRO process since the former is operating at lower hydraulic pressure. Experimental works demonstrated that a high hydraulic pressure promotes membrane fouling $[23,29]$; hence it can be reservedly assumed that the fouling propensity of the optimized PRO system would be also less than that in the normal PRO system. 

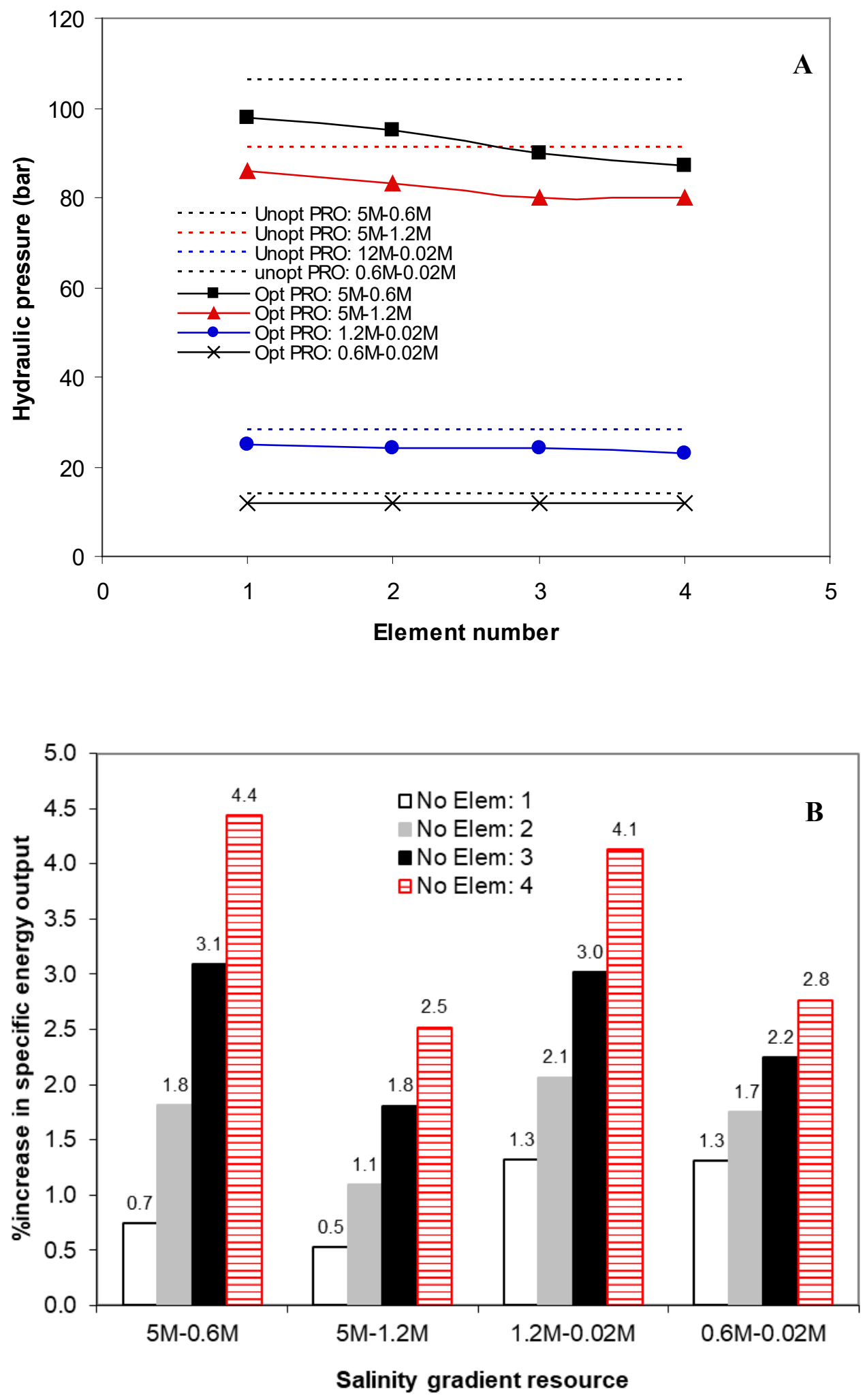


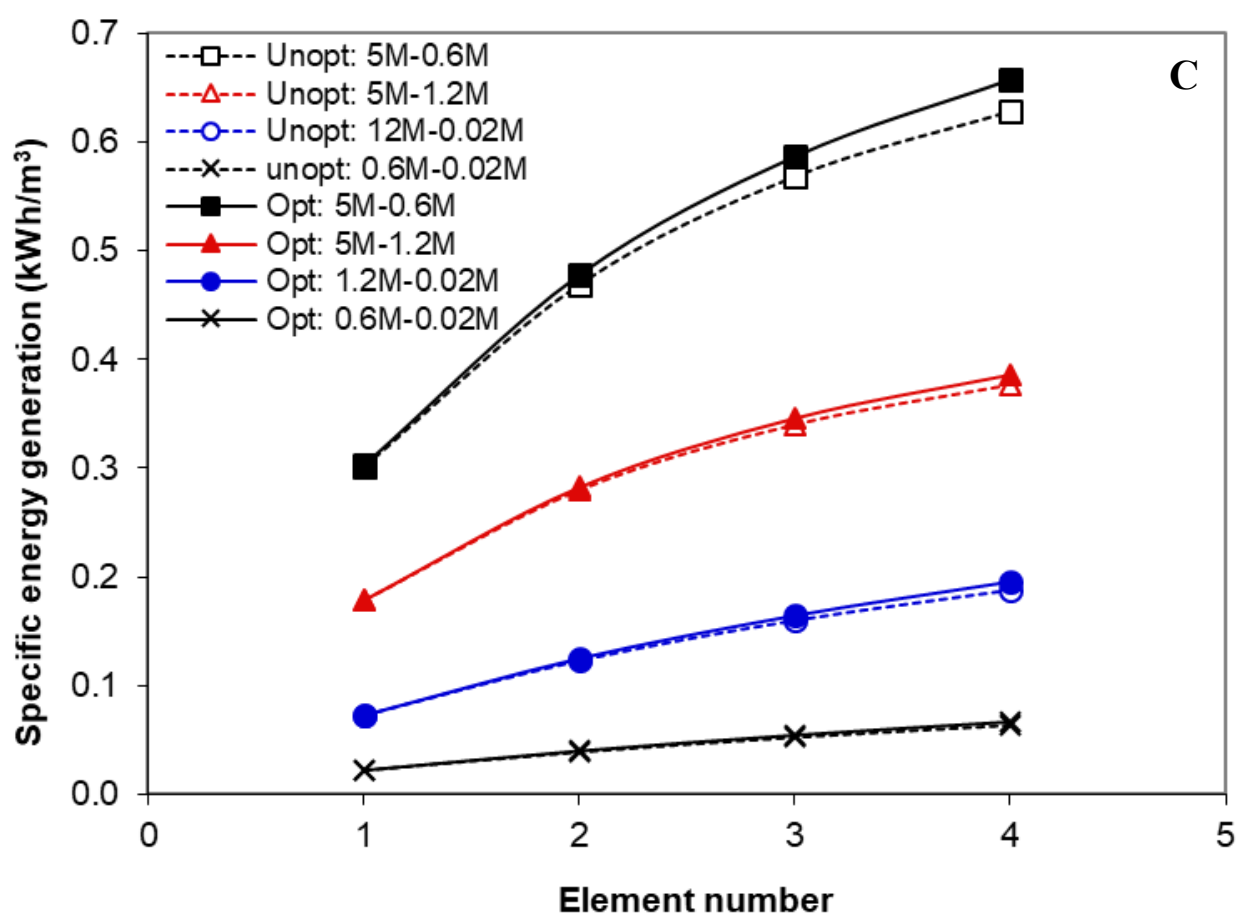

Figure 1: GWO optimization of hydraulic pressure in the PRO process consisting of 1 to 4 modules in the pressure vessel A) hydraulic pressure in optimized PRO and PRO process B) percentage increase in specific energy output in the optimized PRO compared to PRO process $\mathrm{C}$ ) specific power generation in the PRO process. PRO element is 1 meter long, unoptimized PRO process operates at $\Delta P=\Delta \pi / 2$.

\subsection{Optimization of the draw solution flow rate}

Mixing ratio of feed and draw solutions has significant impact on the performance of the PRO process [22]. Elimelech and co-workers demonstrated that a maximum energy output in irreversible PRO process is achieved at $50 \%$ mixing ratio and a hydraulic pressure equal to $\Delta P=\Delta \pi / 2$ [8]. The study ignored the effects of CP in the PRO module, which questions its applicability on field studies. Laboratory scale experiments demonstrated that performance of the osmotically driven processes were highly dependent on the flow rates of draw and feed solutions [22]. We performed a GWO PRO process to determine the optimum flow rate of the draw solution that results in a maximum energy output in a non-ideal PRO process operated at $\Delta P=\Delta \pi / 2$.

Figure 2 shows the optimum volumetric flow rate of the draw solution to maximize the energy yield of the PRO process. For all salinity gradients, the fraction of draw solution, $\theta_{D}$, increased with the number of the PRO modules in the pressure vessel (Figure 2A). Technically, this is to offset the dilution of draw solution in subsequent PRO module and maintain permeation flow across the membrane. The optimum $\theta_{D}$ was less than 0.5 for all salinity gradients and number of PRO modules in the pressure vessel. This contradicts with the findings of previous studies that assumed an ideal PRO process or the impact of feed and draw solution dilution and concentration, respectively, along the PRO module $[8,10,33]$. The optimum $\theta_{D}$ is $0.5,0.48 .0 .48$, and 0.41 for $5 \mathrm{M}-0.6 \mathrm{M}, 5 \mathrm{M}-1.2 \mathrm{M}, 1.2 \mathrm{M}-0.02 \mathrm{M}$, and $0.6 \mathrm{M}-0.02 \mathrm{M}$ salinity gradient, respectively, in 4 elements PRO system. $\theta_{D}$ optimization maximized the energy output in the PRO process as shown in Figure 2B. Compared of an unoptimized PRO process, GWO maximized the specific energy output in the PRO process and resulted in up to $21.9 \%$ higher energy yield in the case of a single module and $0.6 \mathrm{M}-0.02 \mathrm{M}$ salinity gradient (Figure 2B). $0.6 \mathrm{M}-0.02 \mathrm{M}$ salinity gradient demonstrated the largest percentage increase in the energy 
yield due to process optimization followed by $1.2 \mathrm{M}-0.02 \mathrm{M}, 5 \mathrm{M}-1.2 \mathrm{M}$, and $5 \mathrm{M}-0.6 \mathrm{M}$ salinity gradient, respectively. Apparently, 5M-0.6M salinity gradient was less affected by the optimization process than other salinity gradients with $9.9 \%$ increase in a single module PRO process. This was due to the significant osmotic pressure driving force in the $5 \mathrm{M}-0.6 \mathrm{M}$ PRO process, which rendered the increase of the draw solution flow rate less effective in enhancing the osmosis flux. Furthermore, the optimization process had insignificant impact on the energy output in a four-modules PRO process particularly for $5 \mathrm{M}-0.6 \mathrm{M}$ and $5 \mathrm{M}-1.2 \mathrm{M}$ salinity gradients. It is apparent from Figure $2 \mathrm{~A}$ that $\theta_{D}$ values for $5 \mathrm{M}-0.6 \mathrm{M}$ and $5 \mathrm{M}-1.2 \mathrm{M}$ salinity gradients using four modules was 0.5 and 0.49 , which make the operating conditions similar to that in an unoptimized PRO process. Optimization process resulted in a $2.4 \%$ and $0.1 \%$ increase in the energy output in $0.6 \mathrm{M}-0.02 \mathrm{M}$ and $1.2 \mathrm{M}-0.02 \mathrm{M}$ salinity gradients, respectively. For a given salinity gradient, increasing the number of PRO modules results in a larger permeation flow. This requires a higher flow rate to compensate the dilution of draw solution and maintain water flux.

The results suggest that energy yield in the PRO process increases with the number of PRO modules (Figure 4C) because of the larger permeation flow. However, this depends on the quality of feed and draw solutions to avoid membrane fouling [29, 30]. Good pretreatment is required to ensure the quality of feed and draw solutions in a closed-loop PRO process that recycles the draw and feed solutions.

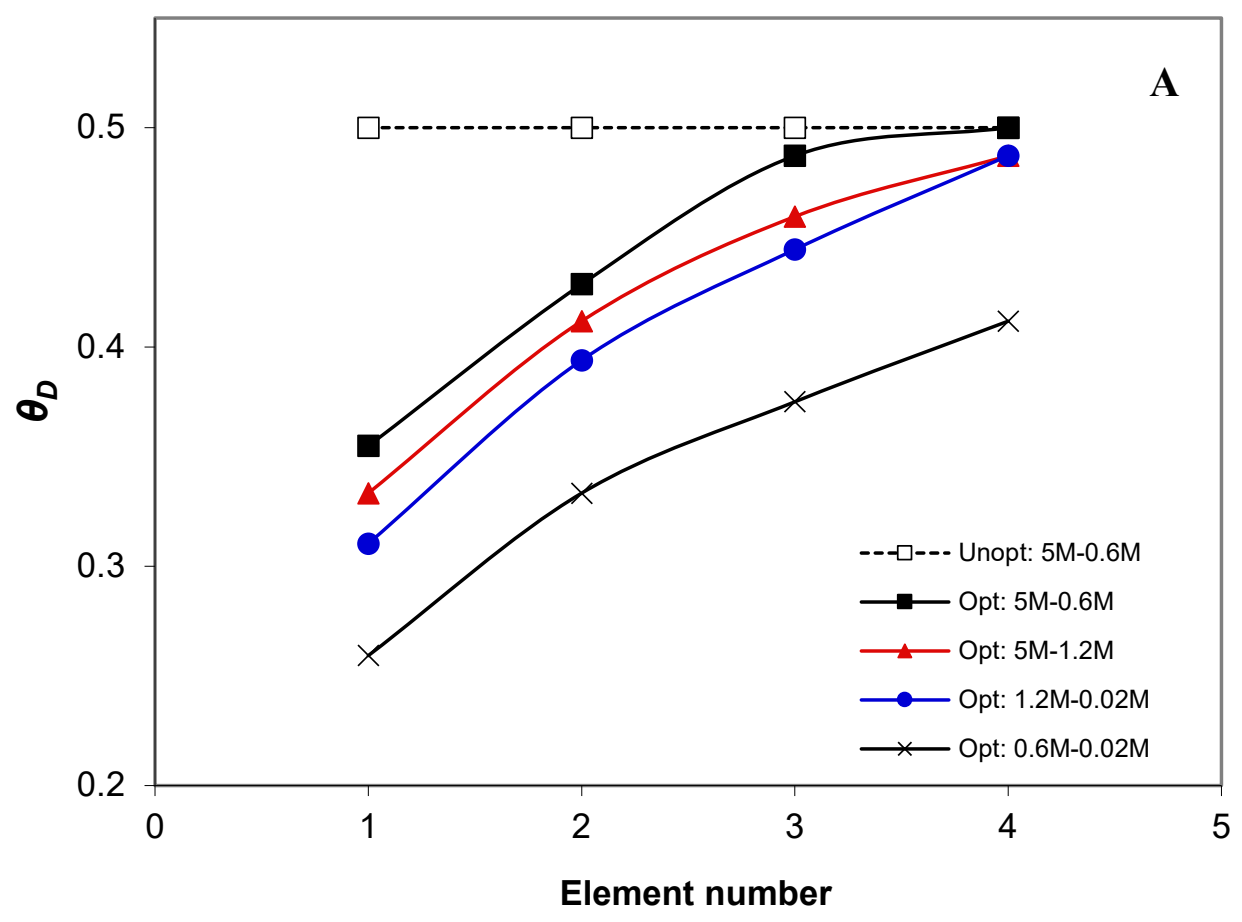



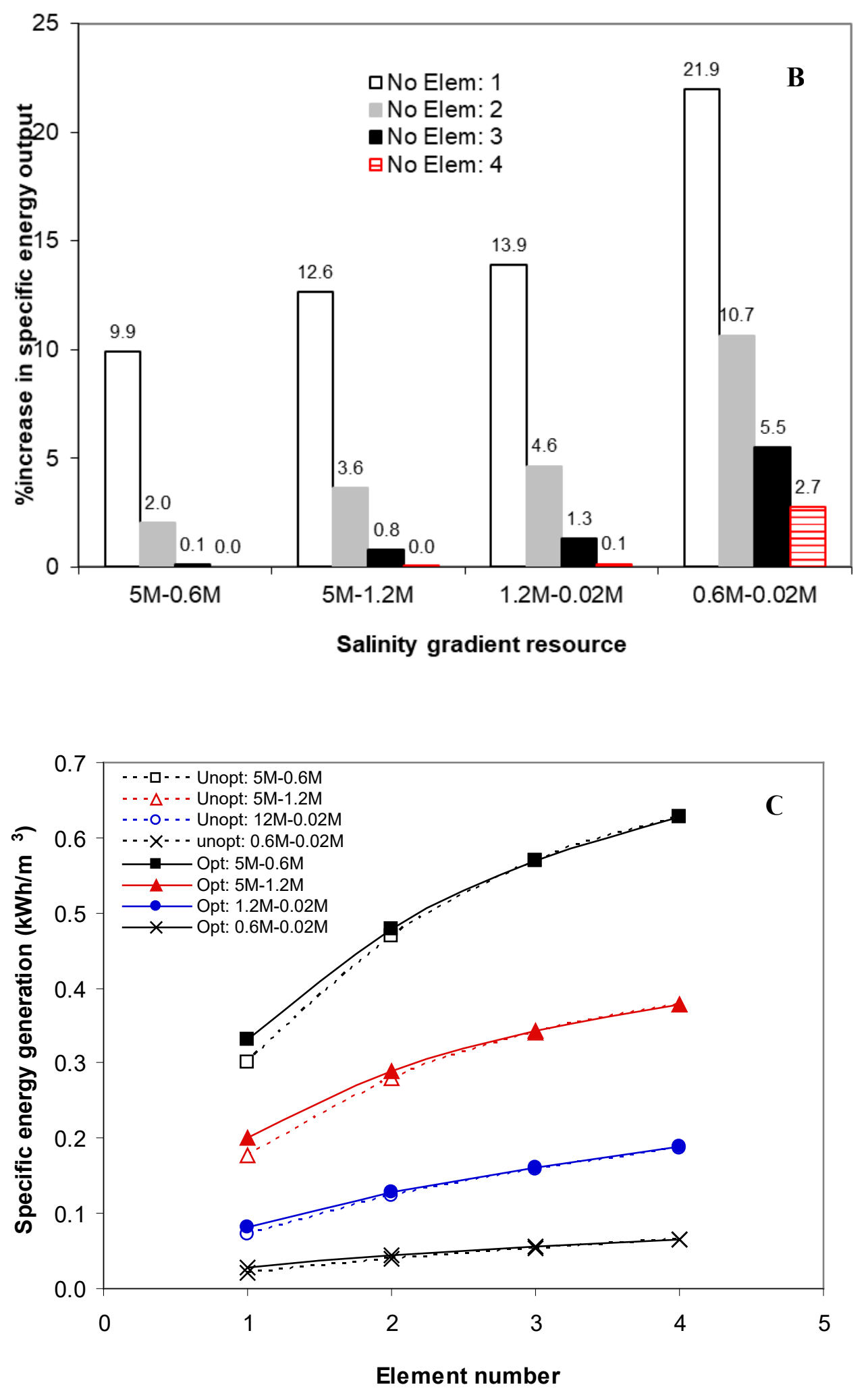

Figure 2: GWO optimization of draw solution fraction in the PRO process A) optimized draw solution fraction, $\theta_{D}$, in PRO system consists of 1 to 4 elements B) percentage increase in specific energy in the optimized PRO compared to a unoptimized PRO process C) impact of number of modules in the PRO process on the specific energy generation. PRO element is 1 meter long, hydraulic feed pressure is $\Delta P=\Delta \pi / 2$. 


\subsection{Optimization of the feed solution flow rate}

Feed solution is an important parameter that affects the performance of the PRO process. Recent studies demonstrated that ICP could be mitigated by changing the flow rate of feed solution [21]. Similarly, the volumetric flow rate of the feed solution needs to be optimized to maximize the energy output of the PRO process. The optimization of feed solution flow rate was carried out using GWO method (Figure 3). Compared to unoptimized PRO operating at $\Delta P=\Delta \pi / 2$ and 0.5 feed solution fraction in the mixture, $\theta_{F}$ was less than $50 \%$ in the optimized process for all salinity gradient resources (Figure $3 \mathrm{~A}$ ). For $5 \mathrm{M}-0.6 \mathrm{M}$ and $5 \mathrm{M}-1.2 \mathrm{M}$ salinity gradients, $\theta_{F}$ increased with the number of PRO modules in the pressure vessel but was higher in the $5 \mathrm{M}-0.6 \mathrm{M}$ salinity gradient (Figure $3 \mathrm{~A}$ ). The optimized $\theta_{F}$ in the $1.2 \mathrm{M}-0.02 \mathrm{M}$ was equal to that in the $0.6 \mathrm{M}-0.02 \mathrm{M}$ salinity gradient but lower than that in the $5 \mathrm{M}-0.6 \mathrm{M}$ and $5 \mathrm{M}-1.2 \mathrm{M}$ salinity gradients. In fact, the optimized $\theta_{F}$ value was $9 \%$ in a single PRO module system and increased to $13 \%$ in two to four PRO modules system. The optimized, $\theta_{F}$ for 4 elements PRO system is $0.31,0.36,0.13$, and 0.13 for $5 \mathrm{M}-0.6 \mathrm{M}, 5 \mathrm{M}-1.2 \mathrm{M}, 1.2 \mathrm{M}-0.02 \mathrm{M}$, and $0.6 \mathrm{M}-0.02 \mathrm{M}$ salinity gradient, respectively. Optimization of $\theta_{F}$ resulted in a considerable improvement in the energy output in the PRO process (Figure 3B). Between $9.4 \%$ and $70.2 \%$ higher energy yield was achieved in the PRO process due to the optimization of $\theta_{F}$. The maximum energy yield in the PRO process decreased with the number of PRO modules in the pressure vessel. This was probably due to the higher ICP effects in the subsequent PRO modules in the pressure vessel. The largest percentage increase in the specific energy was $70.2 \%$ in a single module PRO process and $0.6 \mathrm{M}-0.02 \mathrm{M}$ salinity gradient followed by $69 \%, 33.6 \%$ and $28.3 \%$ for $1.2 \mathrm{M}-0.02 \mathrm{M}, 5 \mathrm{M}-0.6 \mathrm{M}$, and $5 \mathrm{M}-1.2 \mathrm{M}$ salinity gradient resource, respectively. $5 \mathrm{M}-1.2 \mathrm{M}$ salinity gradient had the lowest percentage of energy output increase due to $\theta_{F}$ optimization because of the high concentration of feed solution. In contrast, $1.2 \mathrm{M}-0.02 \mathrm{M}$ and $0.6 \mathrm{M}-0.02 \mathrm{M}$ salinity gradients demonstrated a large improvement in the energy yield due to the low feed concentration that can be relatively easy to alleviate. Technically, ICP can be decreased by increasing the flow rate of the feed solution but it is less effective at high feed concentrations due to the intensive ICP. $\theta_{F}$ optimization has a greater impact than $\theta_{D}$ on the extractable specific energy from salinity gradients. Therefore, in the optimization process of the PRO the impact of $\theta_{F}$ on the specific energy generation should to be considered seriously.

$\theta_{F}$ optimization increased the energy output in the PRO process. The maximum specific energy generation in four modules PRO process was $0.73,0.41,0.29$, and $0.098 \mathrm{kWh} / \mathrm{m}^{3}$ for $0.5 \mathrm{M}-0.6 \mathrm{M}, 5 \mathrm{M}-1.2 \mathrm{M}, 1.2 \mathrm{M}-0.02 \mathrm{M}$, and $0.6 \mathrm{M}-0.02 \mathrm{M}$ salinity gradients, respectively. The corresponding $\theta_{F}$ ratios were $31,35,13$, and $13 \%$, respectively (Figure 3C). Theoretically, it was possible to use low feed flow rates in order to maximize the energy output but that will strongly depend on the quality of feed solution and the pretreatment method. The results show that $\theta_{F}$ was more effective than $\theta_{D}$ to improving the specific energy output in the PRO process due to the complicated nature of the ICP that occurs in the support layer and affect the permeation flow in the PRO process $[1,19]$. Mitigation of ICP is possible through increasing the feed flow rate as indicated in recent studies $[21,22]$. Furthermore, comparing Figures $2 \mathrm{~A}$ and $3 \mathrm{~A}$ shows that $\theta_{F}$ was lower than $\theta_{D}$ for all salinity gradient resources; i.e. lower feed to draw solution ratio. At low $\theta_{F}$ ratio, the concentration of draw solution would be sufficiently highly in the subsequent PRO modules to maintain the permeation flow and specific energy generation. Using low feed flow rates, however, is not always practically feasible and it depends on the quality of feed solution. With low quality feed flow rates, the propensity of membrane fouling would be high and there is a risk to apply low feed flow rates. Though, it is possible to apply low feed flow rates in a closed-loop PRO process in which a pure feed and draw solutions are recycled in the PRO process or when good pretreatment facilities are available. 

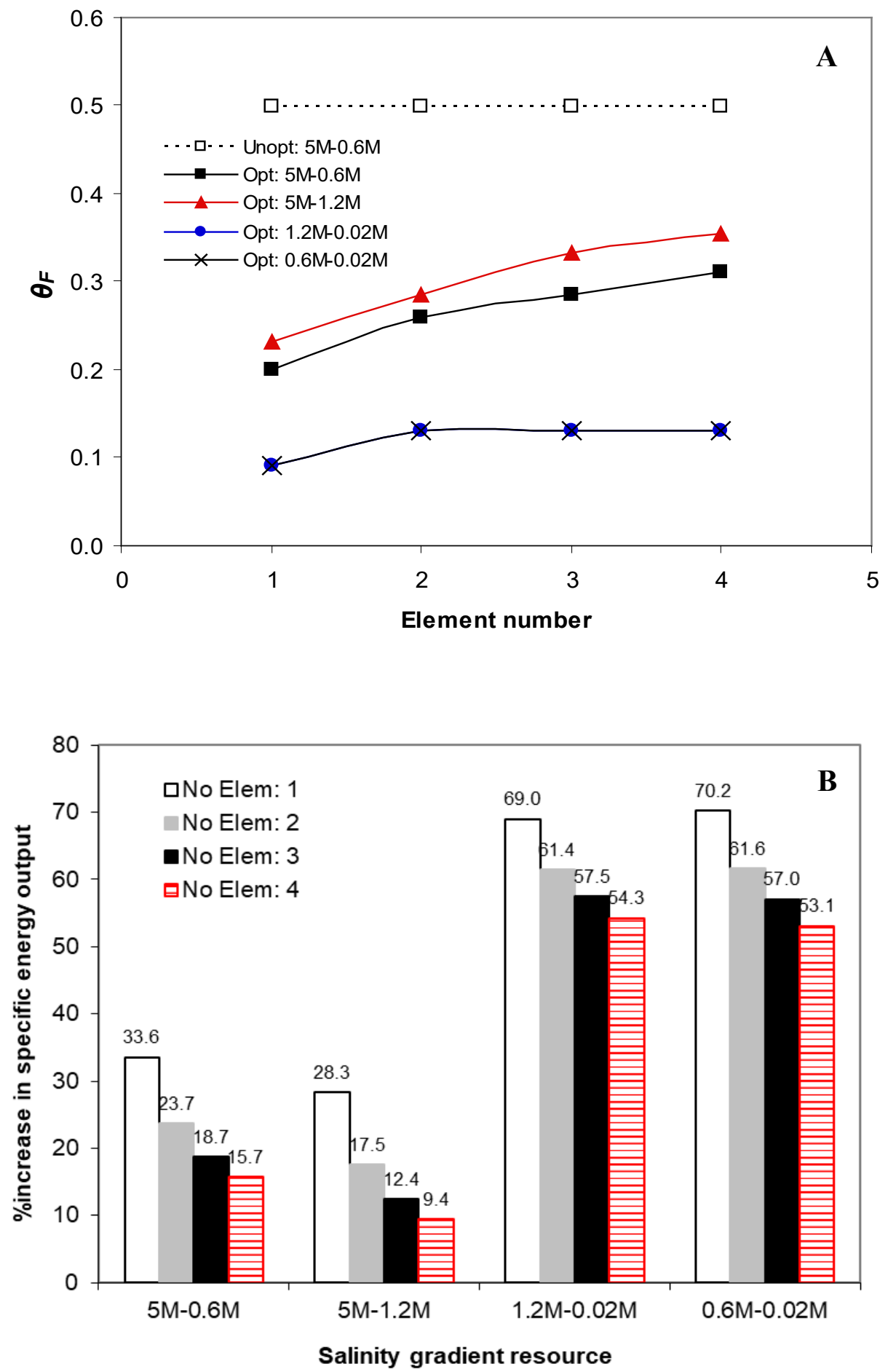


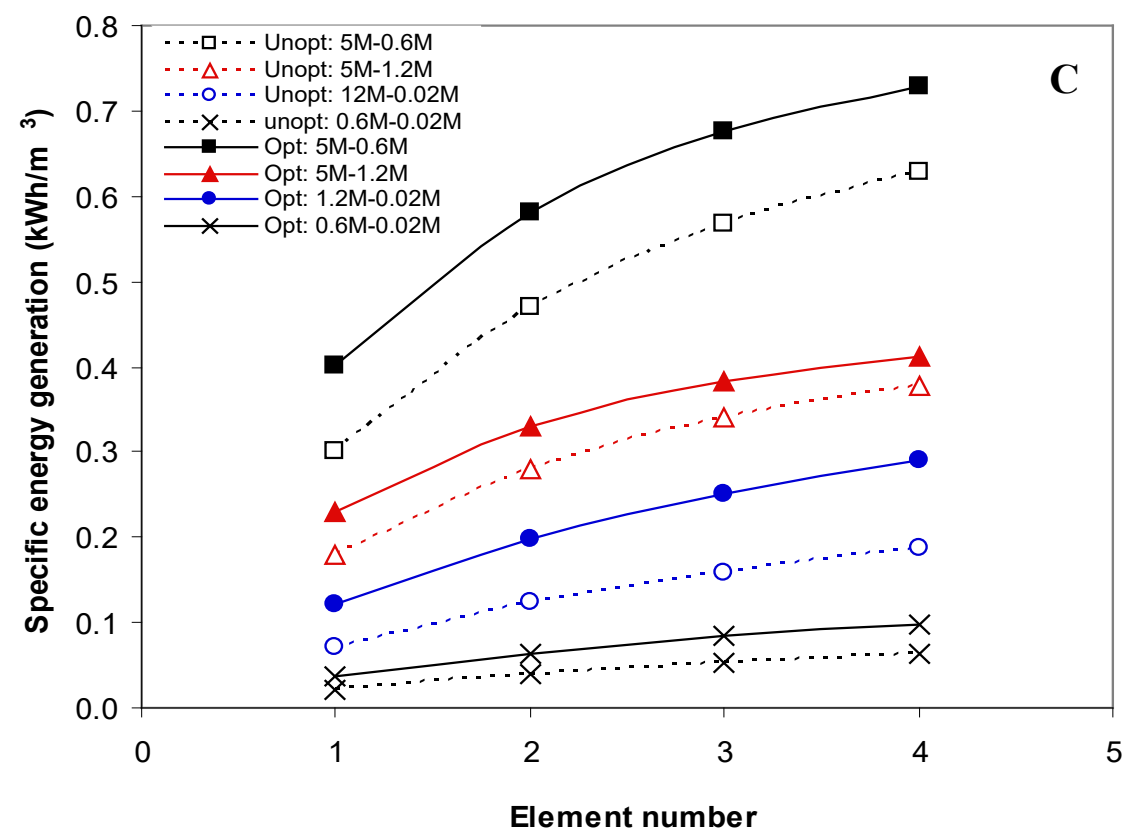

Figure 3: Optimization of feed flow rate, $\theta_{F}$, in PRO system consists of 1 to 4 elements A) optimized feed solution fraction, $\theta_{F}$, in PRO system B) percentage increase in specific energy in the optimized PRO compared to a unoptimized PRO process $\mathrm{C}$ ) impact of number of modules in the PRO process on the specific energy generation. PRO element is 1 meter long and all results were obtained at $\Delta P=\Delta \pi / 2$.

\subsection{Optimization hydraulic pressure and feed flow rate}

Results reveal that the optimization of $\theta_{F}$ was more effective than $\theta_{D}$ in improving the specific energy generation in the PRO process. Therefore, results from section 3.2 were further evaluated to determine the optimum hydraulic pressure in the PRO process. Optimization was performed for all salinity gradient resources using the optimum $\theta_{F}$ from section 3.2 and the optimum hydraulic pressure was obtained in PRO processes consisting of one to four modules in the pressure vessel (Figure 4). Results in Figure 4A show that the specific energy generation increased with the number of modules in the optimized PRO process and was higher than that in the unoptimized PRO process. The maximum specific energy generation in an optimized PRO process consisting of four modules was $0.75,0.42,0.29,0.10 \mathrm{kWh} / \mathrm{m}^{3}$ for $5 \mathrm{M}-0.6 \mathrm{M}, 5 \mathrm{M}-$ $1.2 \mathrm{M}, 1.2 \mathrm{M}-0.02 \mathrm{M}$, and $0.6 \mathrm{M}-0.02 \mathrm{M}$ salinity gradients, respectively. This was $11.6 \%$ to $58.2 \%$ higher than the specific energy that can be harvested from the same salinity gradients in unoptimized four-modules PRO processes [Figure 4B].

Figure $4 \mathrm{C}$ shows that the percentage increase of the specific energy generation decreased with the number of modules in the PRO process. For example, there was $45 \%$ increase of the maximum energy generation from $5 \mathrm{M}-0.06 \mathrm{M}$ salinity gradient by increasing number of modules from 1 to 2 modules (Figure 2A). Adding a third PRO module, however, resulted in $17 \%$ increase in the energy generation while increasing the number of PRO modules to four brought out only $9 \%$ increase in the energy generation. Furthermore, the optimized PRO process was operated at a hydraulic pressure lower than $\Delta P=\Delta \pi / 2$ that is recommended in an unoptimized PRO process (Figure 4C). The optimum hydraulic pressure predicted by GWO was 2.2 to 16 bar lower than $\Delta P=\Delta \pi / 2$ and always decreases with the number of modules in 
the PRO process (Figure 3C). The optimum pressure for $5 \mathrm{M}-0.6 \mathrm{M}$ salinity gradient was decreased from 100 bar to 89 bar as the number of modules increased from 1 to 4 modules. Compared to an unoptimized PRO process operated at 106 bar, an optimized PRO process consisting of 4 modules required $16 \%$ less hydraulic pressure. $5 \mathrm{M}-0.6 \mathrm{M}$ salinity gradient with four PRO modules demonstrated the largest decrease in the operating pressure, from 106 to 89 bar, followed by $0.6 \mathrm{M}-0.02 \mathrm{M}, 1.2 \mathrm{M}-0.02 \mathrm{M}$, and $5 \mathrm{M}-1.2 \mathrm{M}$ salinity gradient, respectively. For $0.6 \mathrm{M}-0.02 \mathrm{M}$ and $5 \mathrm{M}-1.2 \mathrm{M}$ salinity gradients, there was no change in the optimum operating pressure when the number of modules decreased from 4 to 3 modules. As mentioned before, reducing the operating hydraulic pressure would reduce the size of high pressure pump and pumping energy. Practically, the net energy output in the PRO process should account for all energy input that includes pumping and pretreatment energy of feed and draw solutions.

Furthermore, reverse salt flux in the optimized and unoptimized PRO process is shown in Figure 4D. The results show that reverse salt flux, $J_{S}$, was higher in the unoptimized PRO process compared to the optimized process. This is due to the greater water flux in the unoptimized PRO process imposed by the higher osmotic pressure driving force across the membrane. The optimized POR process operates at lower hydraulic pressure using the same salinity gradient resource in the unoptimized PRO process. As a result, the osmotic pressure driving force would be higher in the optimized PRO process. In an open loop PRO process, where both feed and draw solution are disposed of, reverse salt flux has less impact on the performance PRO process. While in a closed-loop PRO process, it leads to the contamination of feeds' solutions over time.

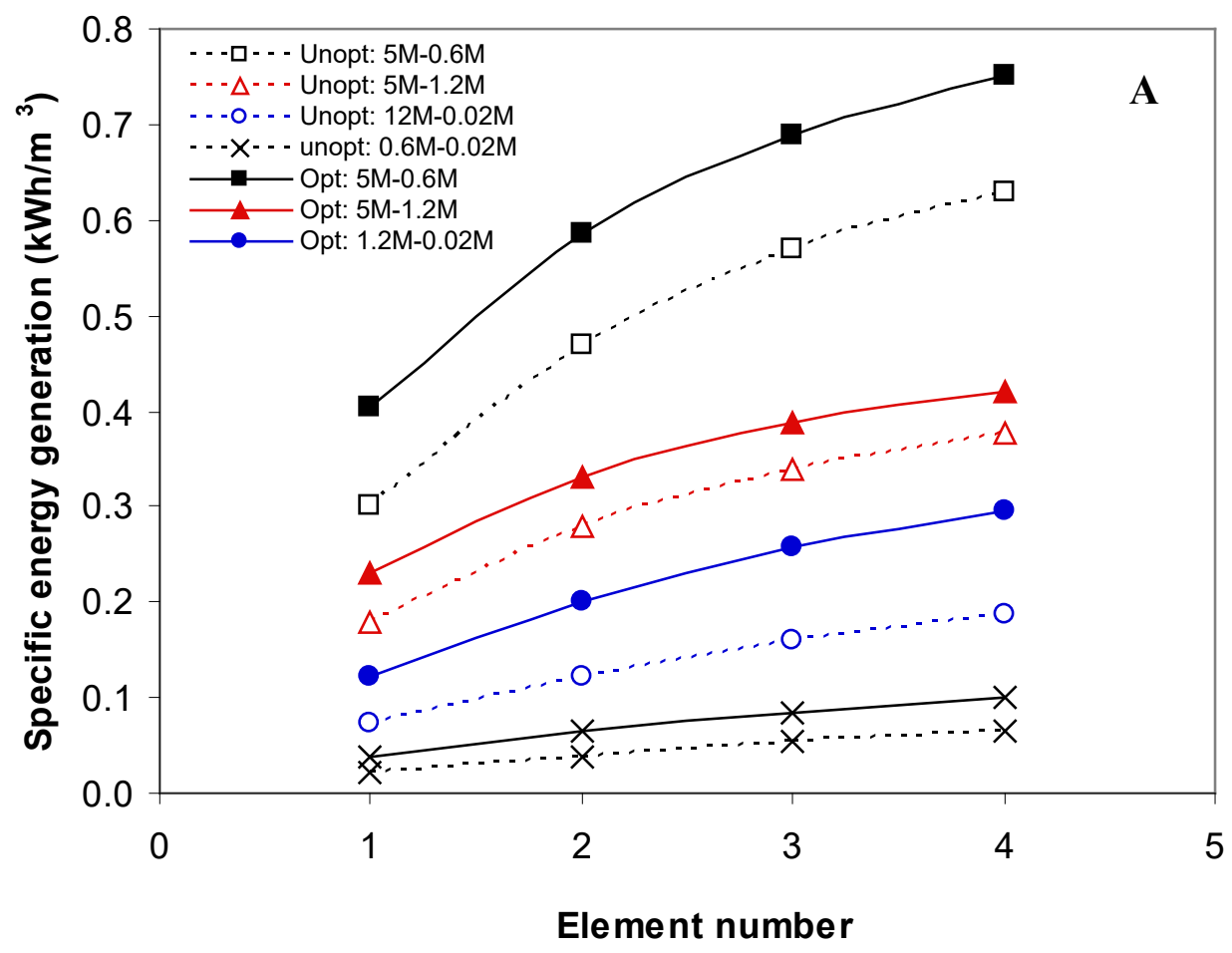



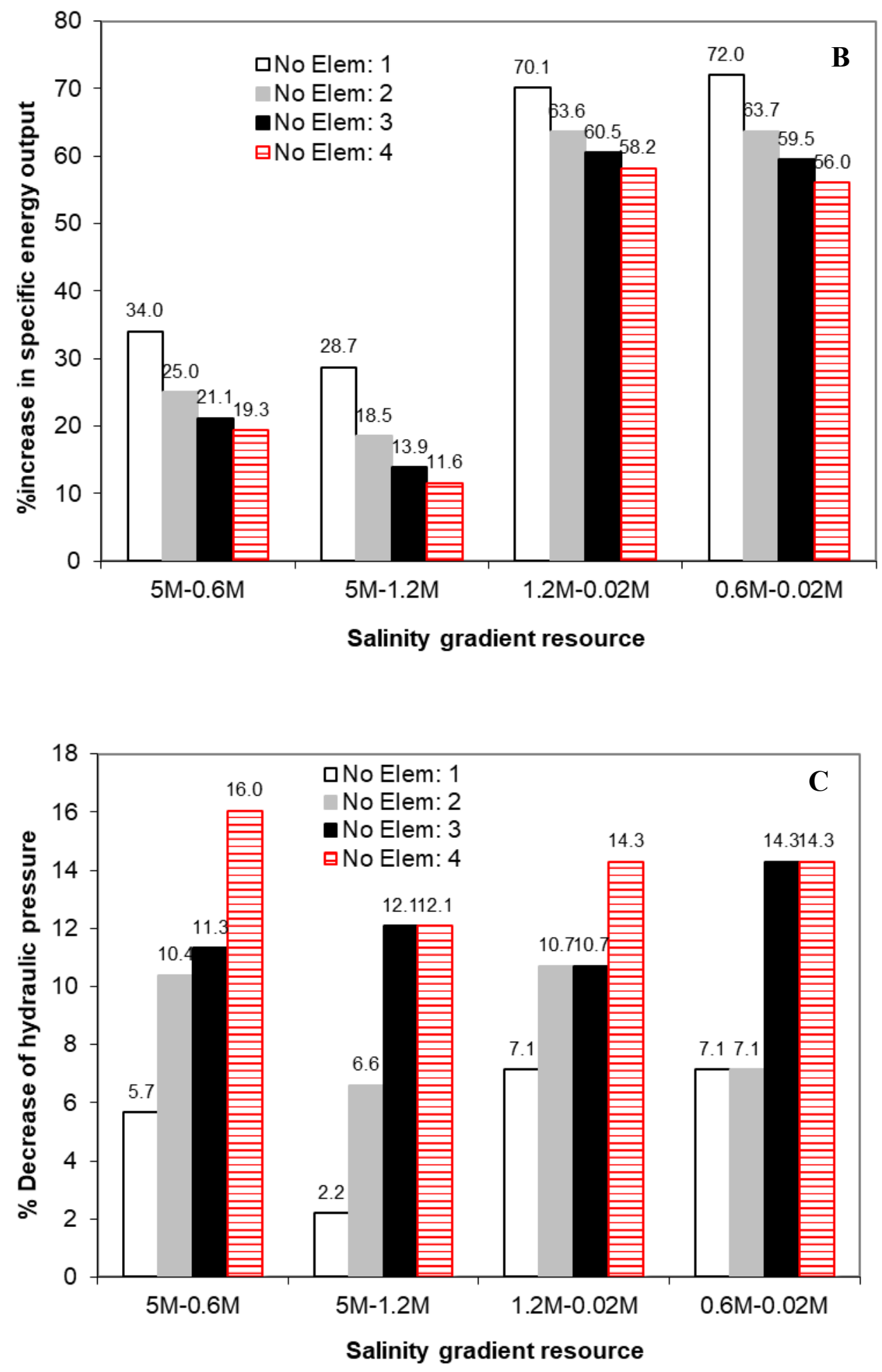


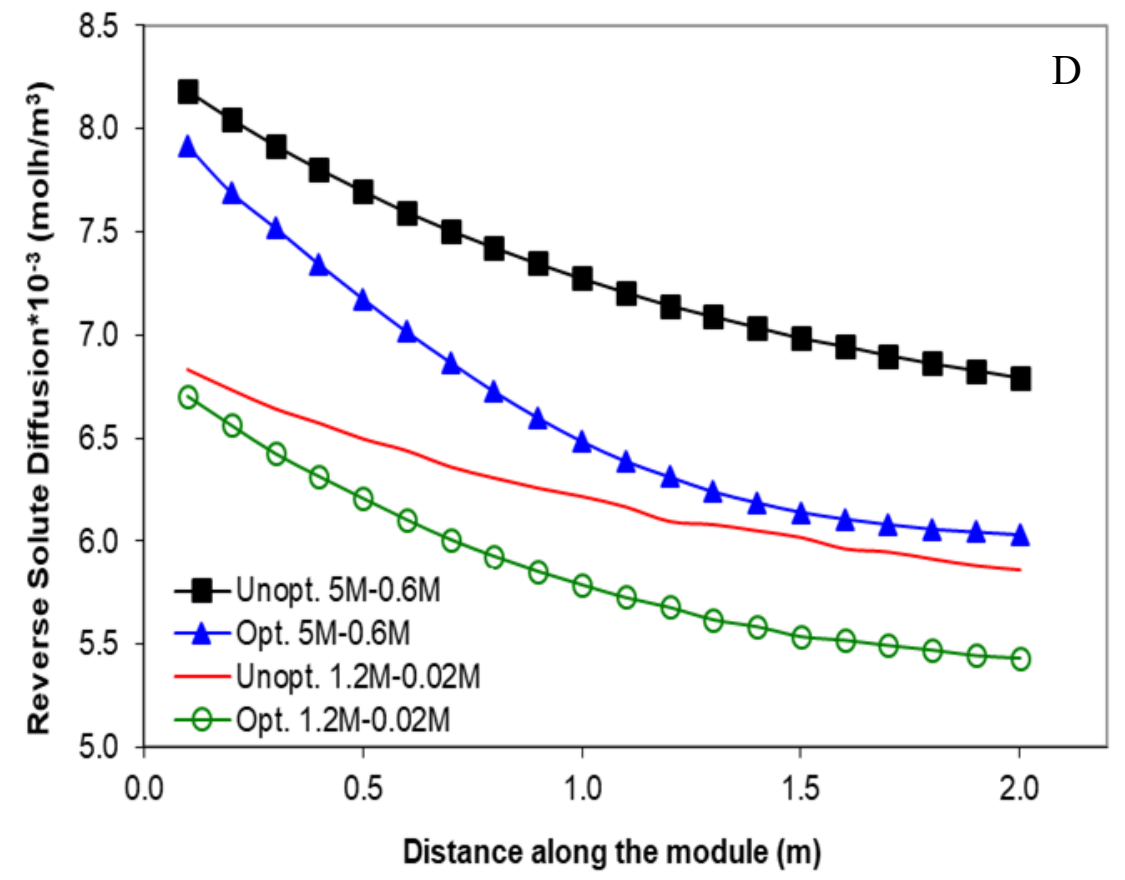

Figure 4: Optimization of hydraulic pressure, $\Delta \mathrm{P}$, in PRO system consists of 1 to 4 elements $\mathrm{A}$ ) impact of number of PRO modules on the specific energy generation B) percentage increase in specific energy in the optimized PRO compared to a unoptimized PRO process C) optimized hydraulic pressure in the PRO process compared to a normal PRO process D) Reverse salt flux in the PRO module. PRO element is 1 meter long, results are already optimized for feed flow rate fraction, $\theta_{F}$.

\section{Power density of PRO modules in pressure vessel}

Power density (W) of the PRO process operating at optimum hydraulic pressure and flow rate is an indicator to the performance of the PRO process according to the following expression:

$W=P_{\text {opt }} * J_{w}$

Where, $P_{\text {opt }}$ is the optimized hydraulic pressure and $\mathrm{Jw}$ is the water flux at optimum hydraulic pressure and feed flow rate. In multi-modules PRO process, the performance of the PRO membrane varies from one module to another across the pressure vessel and hence the average power density of each module was calculated and compared against the minimum threshold of $5 \mathrm{~W} / \mathrm{m}^{2}$ (Altaee et al. 2017). Figure 5 shows the average power density for the optimized feed flow and hydraulic pressure PRO process (section 3.4).

In case of 5M-0.6M PRO system consists of 1 to 4 modules in the pressure vessel, for example, the average power density was more than $5 \mathrm{~W} / \mathrm{m}^{2}$ in all systems [Figure $5 \mathrm{~A}$ ]. In general, the highest power density was $46 \mathrm{~W} / \mathrm{m}^{2}$ in a single PRO system. In multiple modules PRO system, power density decreased from the first to last module in the pressure vessel and reached a lowest amount of $7.5 \mathrm{~W} / \mathrm{m}^{2}$ in the fourth element of 4 modules PRO system. The same profile of power density was observed in $5 \mathrm{M}-1.2 \mathrm{M}$ and $1.2 \mathrm{M}-0.02 \mathrm{M}$ salinity gradients, although the maximum power density was lower than that in the $5 \mathrm{M}-0.6 \mathrm{M}$ salinity gradient resource [Figures 5A\&5B]. The power density in the fourth element of 4 modules PRO system was less than $5 \mathrm{~W} / \mathrm{m}^{2} ; 4.4 \mathrm{~W} / \mathrm{m}^{2}$ and $3.9 \mathrm{~W} / \mathrm{m}^{2}$ for $5 \mathrm{M}-1.2 \mathrm{M}$ and $1.2 \mathrm{M}-0.02$ Salinity gradients, respectively. The underperformance of the fourth PRO element in the PRO process is an 
indicator that the extractable osmosis energy from the salinity gradient resource reached or close to its thermodynamic limits. This scenario is obvious in $0.6 \mathrm{M}-0.02 \mathrm{M}$ salinity gradient resource, which exhibited a lowest performance amongst all other salinity gradient [Figure 5D]. Although optimization process improved the performance of the PRO process, power density in $0.6 \mathrm{M}-0.2 \mathrm{M}$ salinity gradient remained under the minimum threshold the of $5 \mathrm{~W} / \mathrm{m}^{2}$. A maximum power density $3.6 \mathrm{~W} / \mathrm{m}^{2}$ was achieved in the first element while decreased to 1.5 $\mathrm{W} / \mathrm{m}^{2}$ in the fourth element of 4 PRO modules system. The low performance of the optimized PRO system in $0.6 \mathrm{M}-0.02 \mathrm{M}$ salinity gradient resource is due to the unsatisfactory net osmosis driving force across the membrane. For all other salinity gradients, the performance of the PRO modules was mostly acceptable apart from the fourth PRO element in $5 \mathrm{M}-1.2 \mathrm{M}$ and $1.2 \mathrm{M}$ $0.02 \mathrm{M}$ salinity gradients. The results also reveal that the average maximum power density in each PRO module can be determined in each module in the pressure vessel and track down PRO module of undesirable performance.

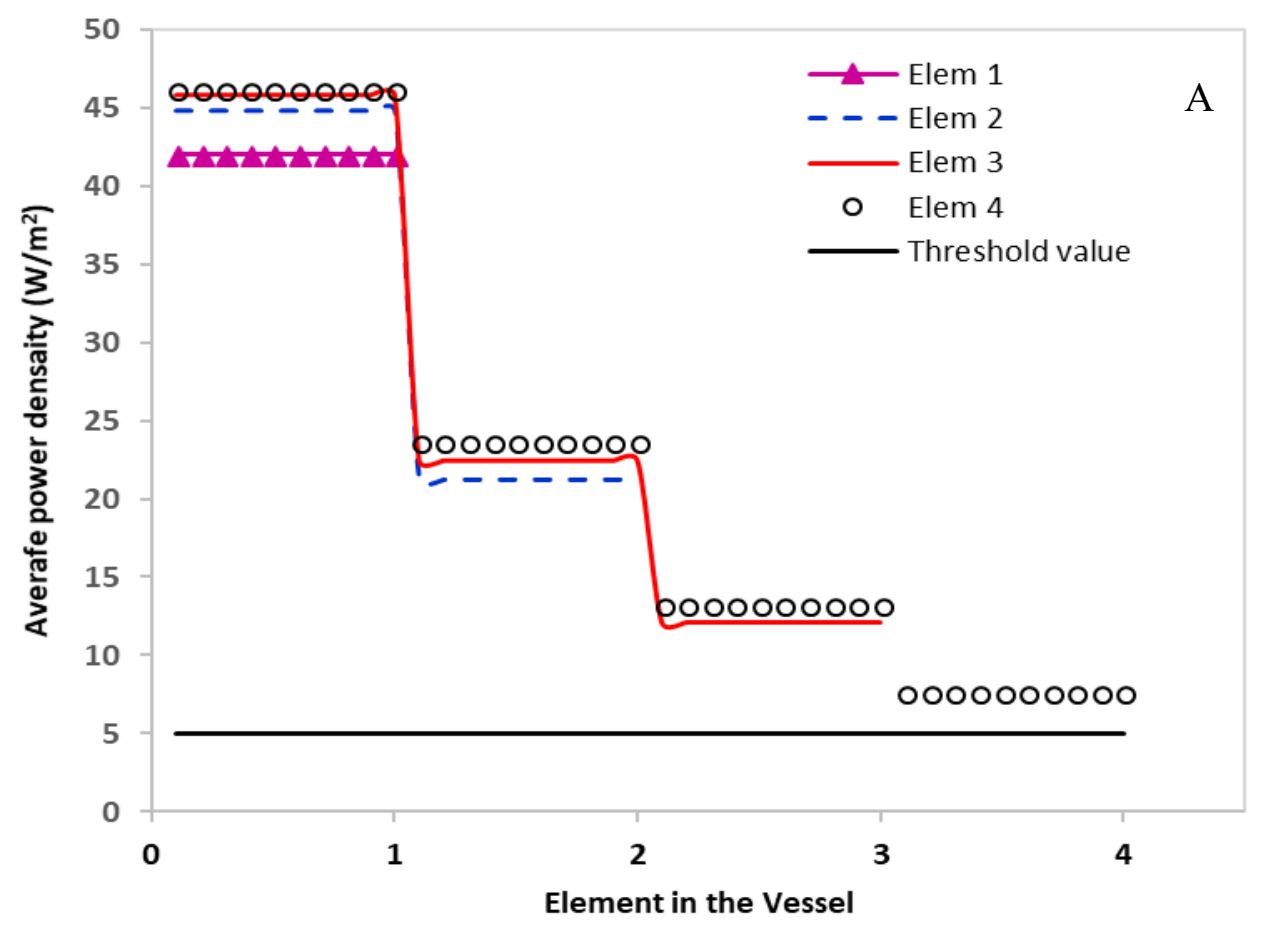



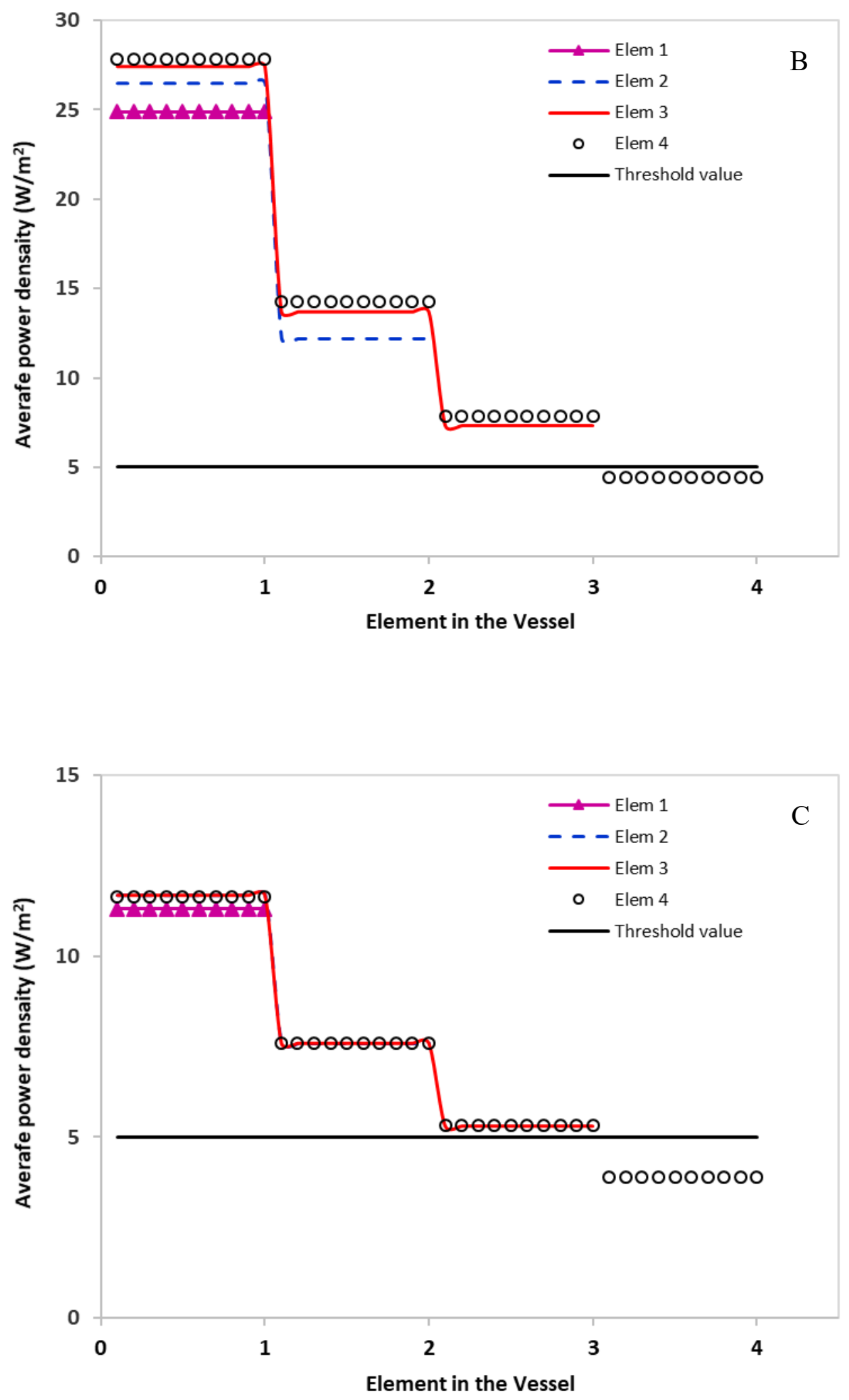


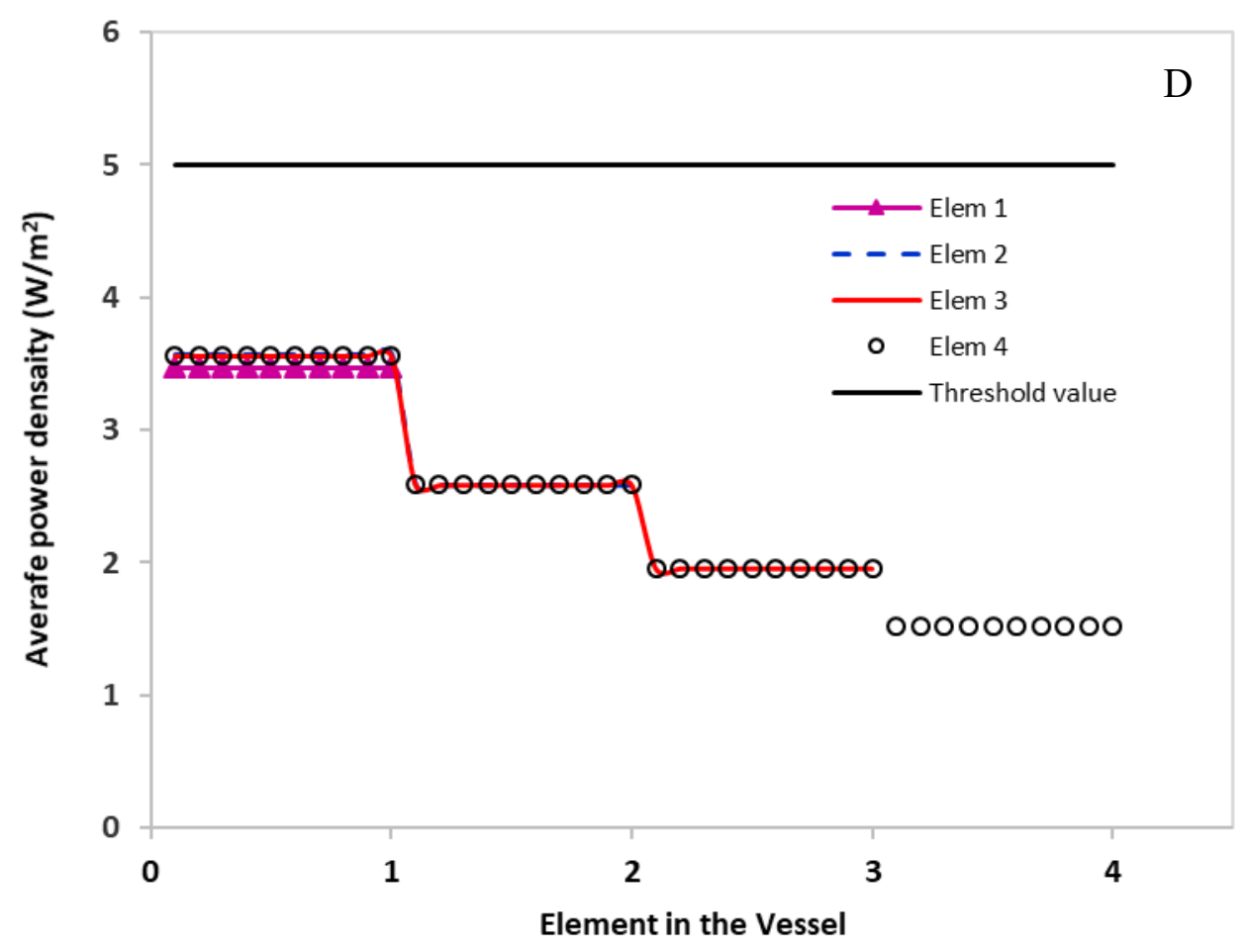

Figure 5: Power density in PRO system of multiple PRO modules A) 5M-0.6M salinity gradient B) 5M-1.2M salinity gradient C) $1.2 \mathrm{M}-0.02 \mathrm{M}$ salinity gradient and D) $0.6 \mathrm{M}-0.02 \mathrm{M}$ salinity gradient

\section{Net power generation in optimized PRO process}

Net energy generation in the PRO process is the difference between the energy output and the energy input that is incurred for the pretreatment of feed and draw solution, pumping, and loss in the pressure exchanger (PX) $[1,31]$. Practically, net power generation is the total useful power harvested from a salinity gradient resource in the PRO process and represent the difference between the energy input and energy output [1]. It is more relevant guidance of the performance of the PRO process than power density since the latter does not account for the energy required for pumping, energy losses, and energy requirements for pretreatment of feed and draw solutions $[33,34]$.

The efficiency of pressure exchanger is assumed 98\% in this study [1]. The breakdown of energy input in the unoptimized PRO is detailed in a previous work [1] and presented in table 2. The total energy input in the optimized PRO (opt) was slightly lower than that in the unoptimized (unopt) process due to the lower operating pressure in the former process (Table 2). This will reduce the operating and capital cost of the PRO process since the high-pressure pump and membrane are made to lower specifications. Table 2 shows that the net energy output in the optimized PRO process consisting of 4 modules is higher than that in the unoptimized PRO process. The energy output was $67 \%$ higher in the optimized $5 \mathrm{M}-0.6 \mathrm{M}$ PRO process compared to the unoptimized PRO process; $0.32 \mathrm{kWh} / \mathrm{m}^{3}$ and $0.191 \mathrm{kWh} / \mathrm{m}^{3}$, respectively. $5 \mathrm{M}-1.2 \mathrm{M}$ salinity gradient showed $14.5 \%$ increase in the energy output upon the optimization. For $1.2 \mathrm{M}-0.02 \mathrm{M}$, the net energy output was almost doubled in the optimized PRO process compared to unoptimized PRO process. Unfortunately, $0.6 \mathrm{M}-0.02 \mathrm{M}$ salinity gradient requires 
more energy input than output for both optimized and normal PRO process and hence it may be unsuitable for the PRO application for power generation.

In general, optimization of the operating parameters effectively improved the energy output in the PRO process. Depending on the type of the salinity gradient recourse, optimization of the PRO process resulted in up to $200 \%$ increase of the energy output. Furthermore, the optimized PRO process can be operated at hydraulic pressures lower than that in the unoptimized PRO process. The results also revealed that the operating pressure and mixing ratio of feed or draw solution in the mixture to achieve a maximum energy output in a full scale optimized PRO process are different to that in a laboratory scale PRO unit or an ideal PRO process. As such, the optimum pressure of $\Delta P=\Delta \pi / 2$ and feed or draw solution fraction of $50 \%$ in the mixture is only valid for a laboratory scale PRO unit or an ideal PRO process. It is noteworthy that upon using low feed flow rates as suggested by the GWO caution should be paid as membrane fouling may occur. However, such concerns are less likely in a closed-loop PRO process or when the pretreatment process is well designed.

Table II: Net energy generation in the optimized and unoptimized PRO processes. Optimization is performed on hydraulic pressure and feed flow rate as described in section 3.4

\begin{tabular}{|c|c|c|c|c|}
\hline \multirow[b]{2}{*}{ Process Description } & \multicolumn{4}{|c|}{ Energy $\mathrm{kWh} / \mathrm{m}^{3}$} \\
\hline & $\begin{array}{l}5 \mathrm{M}- \\
0.6 \mathrm{M}\end{array}$ & $\begin{array}{c}\text { 5M- } \\
1.2 \mathrm{M}\end{array}$ & $\begin{array}{c}1.2 \mathrm{M}- \\
0.02 \mathrm{M}\end{array}$ & $\begin{array}{l}\text { 0.6M- } \\
0.02 M\end{array}$ \\
\hline Pretreatment & 0.3 & 0.15 & 0.05 & 0.225 \\
\hline Pumping from source & 0.03 & 0.015 & 0.015 & 0.03 \\
\hline Pumping in module & 0.05 & 0.05 & 0.05 & 0.05 \\
\hline Loss in PX (unopt) & 0.059 & 0.051 & 0.016 & 0.008 \\
\hline Loss in PX (opt) & 0.050 & 0.04 & 0.01 & 0.007 \\
\hline Total energy input (unopt) & 0.439 & 0.266 & 0.131 & 0.313 \\
\hline Total energy input (opt) & 0.43 & 0.255 & 0.125 & 0.312 \\
\hline Energy output (unopt) & 0.63 & 0.38 & 0.19 & 0.064 \\
\hline Energy output (opt) & 0.75 & 0.42 & 0.30 & 0.1 \\
\hline Net Energy output (unopt) & 0.191 & 0.144 & 0.059 & - \\
\hline Net energy input (opt) & 0.32 & 0.165 & 0.175 & - \\
\hline \%Diff in net energy & 67.5 & 14.5 & $200 \%$ & \\
\hline $\begin{array}{l}\text { Pressure bar (unopt) } \\
\text { Pressure bar (opt) }\end{array}$ & $\begin{array}{c}106 \\
89\end{array}$ & $\begin{array}{l}91 \\
80\end{array}$ & $\begin{array}{l}28 \\
24 \\
\end{array}$ & $\begin{array}{l}14 \\
12 \\
\end{array}$ \\
\hline
\end{tabular}

Despite the promising potential of PRO for power generation, it suffers from environmental and technical limitations such as the availability of salinity gradients and a suitable PRO membrane [1]. For example, the energy generation in the PRO process depends highly on the concentration of draw solution and such concentration is not always available and easy to tap into it. On the other hand, seawater-wastewater $(0.6 \mathrm{M}-0.02 \mathrm{M})$ salinity gradient is not a promising resource for power generation as shown in table 1. PRO membrane is another challenge that should be considered in the PRO process especially when a high hydraulic pressure is suggested in the operation of the PRO process. For example, 5M-0.6M and 5M$1.2 \mathrm{M}$ salinity gradients require over $80 \mathrm{bar}$ in order to the energy generation to reach the maximum amount. Such PRO membrane is not available yet unless and using RO membrane results in sever concentration polarization effects. Nevertheless, RO brine-wastewater $(1.2 \mathrm{M}-$ $0.02 \mathrm{M}$ ) salinity gradient has significant potential since there are several RO plants and wastewater treatment plant operate in close proximity. The advantage of RO brine-wastewater 
salinity gradient is that $\mathrm{RO}$ brine does not require pretreatment or pumping from source and operate at 23 bar optimum hydraulic pressure that can be delivered by Toyobo hollow fibre PRO module [1].

\section{Conclusion:}

The study evaluated the performance of the PRO process using GWO method to optimize key operating parameters for a number of common salinity gradient resources. The optimized PRO process demonstrated $14.5 \%$ to $200 \%$ higher energy output compared to the unoptimized PRO process. This shows the significance of performing process optimization in engineering fields. The study revealed that the optimum operating pressure and mixing ratios in the laboratory-scale PRO process are not valid in an ideal and full-scale PRO process. The optimized PRO process can be operated at lower pressure and feed or draw solution fractions in mixture than an ideal PRO system. The optimized hydraulic pressure in 4 elements PRO system is $87,80,23$, and 12 bar for $5 \mathrm{M}-0.6 \mathrm{M}, 5 \mathrm{M}-1.2 \mathrm{M}, 1.2 \mathrm{M}-0.02 \mathrm{M}$, and $0.6 \mathrm{M}-0.02 \mathrm{M}$ salinity gradient, respectively. The corresponding energy generation in the PRO system is $0.404,0.23,0.12$, and $0.038 \mathrm{kWh} / \mathrm{m} 3$ for $5 \mathrm{M}-0.6 \mathrm{M}, 5 \mathrm{M}-1.2 \mathrm{M}, 1.2 \mathrm{M}-0.02 \mathrm{M}$, and $0.6 \mathrm{M}-0.02 \mathrm{M}$ salinity gradient, respectively. Furthermore, the energy output in the PRO process increased with increasing the number of the PRO module from 1 to 3 modules but a slight improvement in the energy output was achieved by adding a fourth module. Most of the investigated salinity gradients showed potential for commercial applications apart from $0.6 \mathrm{M}-0.02 \mathrm{M}$ because of the insufficient energy generation. The study also reveals the importance of applying machinelearning approaches such as GWO method in the optimization of engineering systems.

\section{Appendix:}

\section{A.1 Model validation:}

The PRO model in Equation was validated using experimental data from pilot study by Yasuhiko et al., [32]. According to the study, $1.0 \mathrm{M} \mathrm{NaCl}$ and De-ionised water were, respectively, the draw and feed solution in the PRO process. Furthermore, the membrane area is $70 \mathrm{~m}^{2}$, salt permeability coefficient is 0.035 , water permeability coefficient is $0.27 \mathrm{~L} / \mathrm{m}^{2} \mathrm{~h}$ bar and membrane structure parameter is $1038 \mu \mathrm{m}$ [32]. Results from the computer model showed more than $92 \%$ agreement with the experimental data. 


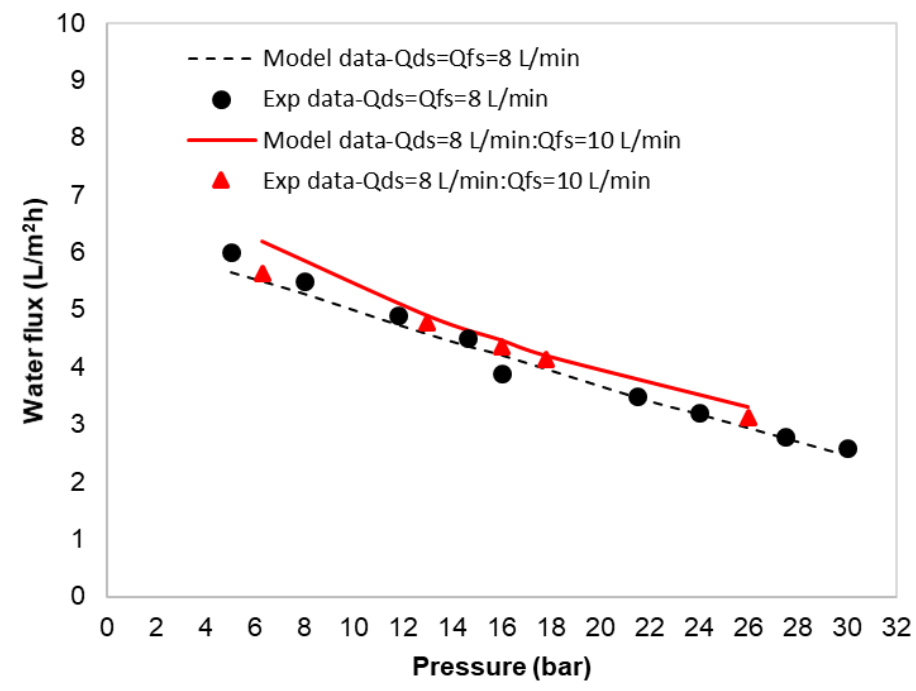

Figure 1: Experimental and theoretical water flux, draw solution $1.0 \mathrm{M} \mathrm{NaCl}$ and FS DI water. Membrane area and water permeability coefficient were $70 \mathrm{~m}^{2}$ and $0.27 \mathrm{~L} / \mathrm{m}^{2} \mathrm{~h}$. bar, respectively. $Q_{\mathrm{ds}}$ is the flow rate of draw solution; $\mathrm{Q}_{\mathrm{fs}}$ is the flow rate of feed solution.

\section{A.2 Problem Description}

The maximization process is subject to the constraints as below. The problem is mathematically formulated as follows:

Consider:

$$
x=\left[x_{1} x_{2}, x_{3}\right]
$$

Objective function: $f(x)=\max (E(x))$

Constraints: $\quad x \geq$ lower boundary

$$
x \leq \text { higher boundary }
$$

In which $x_{1} x_{2}, x_{3}$ are the hydraulic pressure, feed flow rate fraction and draw flow rate fraction, respectively.

\section{A.3 Application of GWO in MPPT Design}

The fitness function of the GWO algorithm is defined to find three best solutions values $\alpha, \beta$ and $\gamma$ as

$$
E\left((\vec{x})_{i}^{k}\right)>E\left((\vec{x})_{i}^{k-1}\right)
$$

In the mathematical optimization model, the solution of the current search agent is defined as

$$
\begin{gathered}
\overrightarrow{D_{\alpha}}=\left|\overrightarrow{C_{1}} \cdot \overrightarrow{X_{\alpha}}(k)-\vec{X}(k)\right| \\
\overrightarrow{X_{1}}(k+1)=\overrightarrow{X_{\alpha}}(k)-\overrightarrow{A_{1}} \cdot \overrightarrow{D_{\alpha}} \\
\overrightarrow{D_{\beta}}=\left|\overrightarrow{C_{2}} \cdot \overrightarrow{X_{\beta}}(k)-\vec{X}(k)\right| \\
\overrightarrow{X_{2}}(k+1)=\overrightarrow{X_{\beta}}(k)-\overrightarrow{A_{2}} \cdot \overrightarrow{D_{\beta}}
\end{gathered}
$$




$$
\begin{gathered}
\overrightarrow{D_{\gamma}}=\left|\overrightarrow{C_{3}} \cdot \overrightarrow{X_{\gamma}}(k)-\vec{X}(k)\right| \\
\overrightarrow{X_{3}}(k+1)=\overrightarrow{X_{\gamma}}(k)-\overrightarrow{A_{3}} \cdot \overrightarrow{D_{\gamma}} \\
\vec{X}(k+1)=\frac{\overrightarrow{X_{1}}(k+1)+\overrightarrow{X_{2}}(k+1)+\overrightarrow{X_{3}}(k+1)}{3}
\end{gathered}
$$

The random parameter $\vec{C} \vec{C}$ is utilized to weight the distance between the search agent and the prey in $[0,2]$. The random coefficient vector $\vec{A} \vec{A}$ of GWO is decreasing as the decline of $\vec{a}$ $\vec{a}$, which is employed to define the searching mode and the attacking mode. During the process, the correlated vector $\vec{a} \vec{a}$ declines following the equation

$$
\vec{a}=2-k * \frac{2}{\text { iter }}
$$

When the global optimum is reached and hunting process finished, the parameter $\vec{a}$ is decreased to 0 .

\section{References:}

[1] Altaee, A., Zhou, J., Alanezi, A.A. and Zaragoza, G., 2017. Pressure retarded osmosis process for power generation: Feasibility, energy balance and controlling parameters. Applied Energy, 206, pp.303-311.

[2] Maisonneuve, J., Laflamme, C.B. and Pillay, P., 2016. Experimental investigation of pressure retarded osmosis for renewable energy conversion: Towards increased net power. Applied energy, 164, pp.425-435.

[3] Altaee, A., Zaragoza, G., Drioli, E. and Zhou, J., 2017. Evaluation the potential and energy efficiency of dual stage pressure retarded osmosis process. Applied Energy, 199, pp.359-369.

[4] He, W., Wang, Y. and Shaheed, M.H., 2015. Maximum power point tracking (MPPT) of a scale-up pressure retarded osmosis (PRO) osmotic power plant. Applied energy, 158, pp.584-596.

[5] Md. Shahidul Islam, Sormin Sultana, Suman Adhikary, Md. Saifur Rahaman, 2018. Highly effective organic draw solutions for renewable power generation by closed-loop pressure retarded osmosis. Energy Conversion and Management, 171, pp. 1226-1236.

[6] Kurihara, M. and Hanakawa, M., 2013. Mega-ton Water System: Japanese national research and development project on seawater desalination and wastewater reclamation. Desalination, 308, pp.131-137.

[7] Skilhagen, S.E., Dugstad, J.E. and Aaberg, R.J., 2008. Osmotic power-power production based on the osmotic pressure difference between waters with varying salt gradients. Desalination, 220(1-3), pp.476-482.

[8] Lin, S., Straub, A.P. and Elimelech, M., 2014. Thermodynamic limits of extractable energy by pressure retarded osmosis. Energy \& Environmental Science, 7(8), pp.2706-2714.

[9] Nagy, E., 2014. A general, resistance-in-series, salt-and water flux models for forward osmosis and pressureretarded osmosis for energy generation. Journal of Membrane Science, 460, pp.71-81.

[10] Achilli, A., Cath, T.Y. and Childress, A.E., 2009. Power generation with pressure retarded osmosis: An experimental and theoretical investigation. Journal of membrane science, 343(1-2), pp.42-52.

[11] Yang, W., Song, L., Zhao, J., Chen, Y. and Hu, B., 2018. Numerical analysis of performance of ideal countercurrent flow pressure retarded osmosis. Desalination, 433, pp.41-47.

[12] Li, M., 2017. Systematic analysis and optimization of power generation in pressure retarded osmosis: Effect of multistage design, AIChE Journal, 64, 144-152.

[13] Li, M., 2014. Analysis and optimization of pressure retarded osmosis for power generation. AIChE Journal, 61, p. 1233-1241.

[14] Mirjalili, S., Mirjalili, S.M. and Lewis, A., 2014. Grey wolf optimizer. Advances in engineering software, 69, pp.46-61.

[15] Mohanty, S., Subudhi, B. and Ray, P.K., 2017. A grey wolf-assisted perturb \& observe MPPT algorithm for a PV system. IEEE Transactions on Energy Conversion, 32(1), pp.340-347.

[16] Islam, H., Mekhilef, S., Shah, N.B.M., Soon, T.K., Seyedmahmousian, M., Horan, B. and Stojcevski, A., 2018. Performance Evaluation of Maximum Power Point Tracking Approaches and Photovoltaic Systems. Energies, 11(2), p.365.

[17] Yang, B., Zhang, X., Yu, T., Shu, H. and Fang, Z., 2017. Grouped grey wolf optimizer for maximum power point tracking of doubly-fed induction generator based wind turbine. Energy conversion and management, 133, pp.427-443. 
[18] Sultana, U., Khairuddin, A.B., Mokhtar, A.S., Zareen, N. and Sultana, B., 2016. Grey wolf optimizer based placement and sizing of multiple distributed generation in the distribution system. Energy, 111, pp.525-536.

[19] Azizivahed, A., Narimani, H., Fathi, M., Naderi, E., Safarpour, H.R. and Narimani, M.R., 2018. Multiobjective dynamic distribution feeder reconfiguration in automated distribution systems. Energy, 147, pp.896914.

[20] Prante, J.L., Ruskowitz, J.A., Childress, A.E. and Achilli, A., 2014. RO-PRO desalination: an integrated lowenergy approach to seawater desalination. Applied Energy, 120, pp.104-114.

[21] Bui, N.N., Arena, J.T. and McCutcheon, J.R., 2015. Proper accounting of mass transfer resistances in forward osmosis: Improving the accuracy of model predictions of structural parameter. Journal of membrane science, 492, pp.289-302.

[22] Altaee, A., Zaragoza, G. and Sharif, A., 2014. Pressure retarded osmosis for power generation and seawater desalination: Performance analysis. Desalination, 344, pp.108-115.

[23] Sarp, S. and Hilal, N. (2018). Membrane-based salinity gradient processes for water treatment and power generation.

[24] Touati, K., 2017. Pressure retarded osmosis: renewable energy generation and recovery, London: Academic Press.

[25] Straub, A.P., Lin, S. and Elimelech, M., 2014. Module-scale analysis of pressure retarded osmosis: performance limitations and implications for full-scale operation. Environmental science \& technology, 48(20), pp.12435-12444.

[26] C. Santhan Kumar and R. S. Rao, "Enhanced Grey Wolf Optimizer Based MPPT Algorithm of PV System Under Partial Shaded Condition," J. Renew. Energy Dev., vol. 6, no. 3, p. 203, 2017.

[27] S. Mohanty, B. Subudhi, and P. K. Ray, "A Grey Wolf-Assisted Perturb \& Observe MPPT Algorithm for a PV System,” IEEE Trans. Energy Convers., vol. 32, no. 1, pp. 340-347, 2017.

[28] Kim, J., Park, M., Snyder, S.A. and Kim, J.H., 2013. Reverse osmosis (RO) and pressure retarded osmosis (PRO) hybrid processes: Model-based scenario study. Desalination, 322, pp.121-130.

[29] She, Q., Zhang, L., Wang, R., Krantz, W.B. and Fane, A.G., 2017. Pressure-retarded osmosis with wastewater concentrate feed: Fouling process considerations. Journal of Membrane Science, 542, pp.233-244.

[30] Abbasi-Garravand, E., Mulligan, C.N., Laflamme, C.B. and Clairet, G., 2018. Investigation of the fouling effect on a commercial semi-permeable membrane in the pressure retarded osmosis (PRO) process. Separation and Purification Technology, 193, pp.81-90.

[31] Straub, A.P., Deshmukh, A. and Elimelech, M., 2016. Pressure-retarded osmosis for power generation from salinity gradients: is it viable?. Energy \& Environmental Science, 9(1), pp.31-48.

[32] Yasuhiko Tanaka, Masahiro Yasukawa, Shohei Goda, Hidehiko Sakurai, Masafumi Shibuya, Tomoki Takahashi, Michimasa Kishimoto, Mitsuru Higa, Hideto Matsuyama, Experimental and simulation studies of two types of 5-inch scale hollow fiber membrane modules for pressure-retarded osmosis, Desalination, V 447 (2018), $133-146$

[33] Altaee A., Cippolina A., 2019. Modelling and optimization of modular system for power generation from a salinity gradient, Renewable Energy, Volume 141, 139-147

[34] Z. X. Wang, D. Y. Hou, S. H. Lin, Gross vs. net energy: Towards a rational framework for assessing the practical viability of pressure retarded osmosis. Journal of Membrane Science, 503, 132-147 (2016). 